\title{
Reconfiguring gender in late modernity
}

\section{Marjolaine Roger}

University of Kent and Université Paris-VIII

H. Bradley

\section{Gender}

Cambridge: Polity Press, 2007, £45.00 hbk, £1 4.99 pbk (ISBN:

978-0-7456-2377-1), ix + 224 pp.

\section{T.L. Caraway}

\author{
Assembling Women: The Feminization of Global Manufacturing \\ New York: Cornell University Press, 2007, £29.50 hbk, £9.95pbk (ISBN: \\ 978-0-80/4-7365-4), xi + 208 pp.
}

\section{A. Nayak and M. J. Kehily}

Gender, Youth and Culture:Young Masculinities and Femininities Basingstoke: Palgrave Macmillan, £52.50 hbk, £1 7.99 pbk (ISBN: 978-1-4039-4977-6), ix + 218 pp.

Reading new, original accounts of the now well researched field of gender is not something one experiences often. Yet the three books reviewed here propose a very interesting take on gender processes in late modernity. Although widely different in their target audience, format and scope, these three publications all reflect upon gendering processes - how an individual, group, job or institution become both socially and culturally gendered.

Bradley's Gender is a very accessible book summarizing the main theories and issues on gender with both a historical and a contemporary outlook. Part of the 'Key Concepts' series from Polity Press, it aims to provide a comprehensive and original overview of gender for students or anyone taking an interest in relations between men and women. After three chapters covering the meaning of gender, modern and postmodern theories, Bradley divides her analysis into the three aspects of gender in society: production, reproduction and consumption. The theoretical chapters are well written and accessible. Through a presentation of the political context, she explains how the major events and ideas of the time shaped the way thinkers elaborated their theories and contributed to paradigm changes. Bradley shares her 
concern about what she calls the two destructive facets of gendering: the constraints placed on women's freedom and choice by their childbearing role, and the suffering imposed on women by men's violence.

Nayak and Kehily's Gender, Youth and Culture also offers an all-round account of gender, with a focus on young people. Social sciences students and researchers will thoroughly enjoy the comprehensive presentation of the changing social and cultural state of youth. The originality of the book is to deal with gender and youth, presenting masculinities and femininities together without necessarily contrasting them. While focusing on a particular age-group is paramount if one wants to understand the lived experience of gender over the life course and across generations, the study of youth is all the more important to understand how processes of gender socialization take place. Moreover, the special attention to popular culture also makes the book very attractive to media students, as it is full of references and thorough analyses of contemporary films and TV series.

In the first part of the book, two key sociological themes are discussed, risk and individualization on the one hand, globalization and postcolonialism on the other hand. Then, the authors discuss the contemporary debates surrounding masculinities and femininities. The study of masculinities draws on Walkerdine's (1990) psychosocial analysis of the reception of Rocky II; the examination of femininities is based on McRobbie's analyses of bedroom cultures in the 1970s (McRobbie, 1978), of rave cultures in the early 1990s (McRobbie, 1994), and more recently of the TV series Sex and the City and the TV programme What Not To Wear (McRobbie, $2004 a, 2004 b)$. They also devote a whole chapter to four critical readings of indepth ethnographies of gender in Brazil, Britain, Russia and Tanzania. These allow us to get a historical and global view of masculine and feminine youth, through a study of rites of passage and subcultures in our postcolonial, post-industrial and global world.

The second part of the book is devoted to the producing, regulating, consuming and performing of gender. It includes a discussion of Skeggs's (1997) research on the moral and social regulation of young women in further education as well as a critique of Butler's (1990, 1993) writings on gender performance and embodiment. In these chapters, the authors also emphasize the significance of space and especially neighbourhoods in the formation of postmodern youth identities.

Caraway's Assembling Women is a powerful presentation of her latest research on the global feminization of workers in manufacturing. It is aimed at postgraduates or researchers with a strong background in qualitative and quantitative analysis and a sound knowledge of economic jargon. Indeed the book addresses specialists of labour markets and the global workforce who wish to understand current processes of feminization and segregation. If the focus is on developing countries and the manufacturing sector the results are useful to understand other cases too.

Her main argument is that employment growth in labour-intensive industries is a primary stimulus for feminization, as it has two effects: increasing the demand for labour and giving the opportunity to subvert gender divisions without reducing the male workforce. While export-oriented industrialization is usually deemed crucial for feminization, for Caraway it is so only insofar as it generates employment 
growth in labour-intensive industries at first, because in the later stages of industrialization capital-intensive industries expand and masculinization ensues.

In the first chapters, Caraway explains that conversely to capital-intensive industries, labour intensity is a determinant of the location of women's employment. She stresses the importance of mediating institutions (a country's politics, history of industrialization, education and family planning policies, and religion) and of gendered discourses of work - on labour, skills, women's versus men's jobs - to explain feminization. Her approach is no doubt innovative in her field: she demonstrates that the reality of women's and men's job skills and attitudes is not important, since it is what employers deem to be true that affects their recruiting practices and development strategies.

Three chapters are then devoted to a case study of Indonesia. After a presentation of the country's economic, social and political context, the three processes at work in feminization are described. 'Stickiness' is the process checking feminization: a certain resistance to (gendered) change always occurs, so most firms wait for men to resign to introduce women; therefore feminization (or masculinization) is more likely to happen if firms expand and create new sections or branches. 'Spillover', on the other hand, fosters feminization. It is the mimetic process whereby one industry will follow the practices of other industries in the same sector or area. If feminization is successful and increases productivity somewhere, then other places will follow. 'Snowballing' also contributes to feminization as this occurs when employment grows rapidly in firms that already employ large proportions of women. These general processes are complemented by a factory-level, multi-sectoral analysis of the phenomenon in four industries: garments, textiles, plywood and automobiles. Paradoxically, highly male-intensive and capital-intensive sectors - which could cut their wages the most by switching to a female workforce - are the least likely to adopt gendered innovations in the labour process, the reason being that the absence of women does not foster fruitful and strategic comparison and subsequent experimenting in introducing women on the shop floor.

A final chapter applies the insights of the case study of Indonesia to a crossregional comparison with nine other countries.

The major assets of these books are the balance of qualitative and statistical data, of personal and general accounts and of trans-disciplinary theoretical developments and case studies. Bradley, Nayak and Kehily combine personal, first-hand ethnographic findings with a myriad of other relevant research findings. Students will particularly relate their own gendered experiences to the testimonies of other young or older people presented there. I particularly enjoyed reading Bradley's Gender: each chapter is followed by a more personal narrative - or 'vignette' - combining individuals' (including the author's) experiences of gender and their theoretical underpinnings. Therefore what makes this book original compared to many textbooks on gender is the powerful combination of personal stories and general research - a clear application of 'the personal is political' of second-wave feminism, to which Bradley is indebted. I also appreciated how some critical discussions in Nayak and Kehily are supported by focus group conversations with younger people and detailed biographies derived from their own ethnographic work. Caraway manages to combine quantitative and qualitative research and analysis: interviews with 
major employers across sectors in Indonesia are combined with two cross-national data sets. This allows her to produce original insights on labour segregation, by combining feminist qualitative research with advanced large-scale statistical analyses, clearly presented in many tables and figures.

\section{Persisting segregation, the crisis of masculinity and the new girl order}

Upon walking into a factory in Indonesia, the visitor is immediately struck by the gender division of labor. Men and women rarely do the same jobs, even when they work in the same area of production, and some sections of production are the exclusive preserve of one gender. (Caraway, pp. 108-9)

The salience of spatial, socio-economic and cultural divides between men and women is widely acknowledged today. However, as stated by Caraway the dynamics of segregation are still poorly understood, even though it is important to study segregation in order to explain the limited effects of the feminization of global labour markets, which have puzzled political economists and second-wave feminists alike. Her book is a very meticulous analysis of these processes at national, sector and firm levels. Her theoretical developments stress the need to focus the explanation of segregation away from the standard feminist explanation of non-market forces, that is to say differential family and reproduction responsibilities borne by men and women. If her demonstration definitely proves the existence and significance of market-based factors for persisting, albeit modified, segregation, her downplaying the weight of family pressures on women's distinct workforce participation can be criticized. Bradley, Nayak and Kehily, on the other hand, offer a more comprehensive account of the various pressures and constraints women face in their daily lives which lead to the production of distinct social and cultural spaces for men and women.

The enduring separation of gender into different spaces may lead us to a reassessment of the 'crisis of masculinity'. According to Morgan (2006), the alleged crisis whereby men become redundant while women are the ideal subjects in a postmodern, globalized, neo-liberal world, is caused by three factors:

1) changes in the labour market, with the rise of the service sector and decline of heavy industries, globalization and increased flexibility;

2) changes in families and intimate life, with rising divorce rates, more femaleheaded, lone-parent families, and lost or weakened links to fathers; and

3) changed positions of women in education, work, and politics.

While Bradley offers a critique of the 'crisis of masculinity' in her vignette ““What's It All About?” Being a Man in the Twenty-First Century?' (pp. 49-58), Nayak and Kehily provide the longest discussion of the debate in their third chapter. Masculinities are seen to be economically and culturally displaced today, and 
popular representations of this 'crisis' are analysed at length in two films, Fight Club and Falling Down. Nayak and Kehily expose the lack of precision surrounding the actual beginning of the crisis of masculinity in most accounts. They also show, through empirical evidence, that loss of masculinity in the workplace does not necessarily result in a crisis in masculinity. Ethnographic data shows that the portrayal of young men in popular media and in some academic work is at odds with their own interpretations of their experiences.

Their most important critique is that the phenomenon needs to be examined through the lens of race and ethnicity: as we see in The Full Monty, mentioned in both Bradley's and Nayak and Kehily's books, the masculinities at stake are white ones, and the concern is about the relocation of manufacturing jobs. Here Caraway's research is useful to understand the gendered processes of these global relocations. Her book is a stark reminder of the fact that increased feminization has not led to more gender equality, as it involves a redrawing of gender boundaries rather than more gender mix: 'inequalities persist because markets reproduce and redraw rather than erase the gendered boundaries in production which perpetuate gender inequalities in the labor market' (p. 14). Thus her research adds supporting evidence to Bradley et al.'s (2000) thesis that the social, economic and political 'female takeover' is a myth.

On the other hand, today's femininities are commonly viewed as the winners of globalization and liberalization. They are redefined as perfect neo-liberal subjects in a 'new girl order', centred upon 'office work, sexual relationships and heady consumerism' (Nayak and Kehily, p. 37). Caraway's description of (young) female workers in Indonesia supports the idea that women are entering the globalized and flexible workforce, but mostly as cheap workers in non-unionized sectors with few career prospects. Bradley, Nayak and Kehily are also critical of an overly optimistic view of young women's situation as they are concerned about new femininities and their excessive display of hyper-sexualized girlhood.

\section{Challenging existing paradigms}

The three books offer a lively critique of the main paradigms in their fields, and all stress the importance of taking into account both the material and the cultural in the analysis of gender.

[G]ender is at the same time both a material and a cultural phenomenon. It refers to both the lived experiences of men and women in relation to each other and to the ideas we develop to make sense of these relations and to frame them. (Bradley, p. 4)

Bradley argues for the usefulness of the sex/gender distinction, as most empirical data shows that 'battles to show that gender is socially constructed are far from won' (p. 21). Thus, Butler's (1990, 1993) work was necessary to show that gender identities are not fixed, but underplays 'the obstinacy of bodies and genital difference' (p. 21) on the one hand, and 'the global market forces of consumer capitalism 
which structure gender relations' (p. 185) on the other hand. So for her, it is necessary to 'mix ideas from modernist and postmodernist frameworks in the study of concrete problems of gender' (p. 76).

The balance between the material and the cultural is present as early as the first chapter of Nayak and Kehily's book: there they manage to combine cultural theory - through the study of youth subcultures and cultural criminology - with sociological and social policy theories - through the British tradition of considering youth as a period of transitions, from school to work, from family of origin to family of destination, and from the family home to the independent home. In Chapter 8, 'Performing Gender', they explain that if queer theories are to retain any significance, they need to engage more fully with everyday life. Therefore they suggest a new concept to understand gender performance: 'gender choreography' - 'a set of culturally patterned activities which bring the subject into being but at best can only ever approximate the sexed identity that is desired' (p. 177). Indeed, new collective 'routines', when repeated and expanded to other social groups, can become acceptable over time and reconfigure gender identity.

Caraway also points to the combination of the material and discursive aspects in what she calls a 'gendered political economy' framework, incorporating four key areas: 'labor/capital intensity, labor supply, mediating institutions, and gendered discourses of work' (p. 32). She offers a critique of conventional political economy views, as she includes feminist critiques, such as the gendered construction of skill. Conventional research sees labour markets as gender neutral, especially Marxist and neo-classic political economy analysis. These have also adopted the optimistic view that feminization is expected to erode gender inequalities, which has been contradicted by last century's trends. Caraway goes further as she insists on the significance of 'gendered discourses of work' which frame employers' attitudes and practices: for instance, women's perceived docility is one driving force behind the feminization of work in some sectors. However, in spite of many feminist accounts showing the historical opposition of unions to female labour, as a resistance to employers' attempts to drive down wages, Caraway seems to be surprised by her finding that strong unions actually have a negative effect on female participation rates.

What remains to be done to reduce gender inequalities? All three books recognize the enduring impact of major changes in the lives of men and women in the past few decades. However, they all have a mixed appraisal of these changes: there has been more a reconfiguration of gendered relations and positions than clear-cut progress, even though some substantial positive changes have occurred.

While Bradley, Nayak and Kehily are optimistic about the future of gender equality and call on the younger generations to carry on subverting gender conformity, Caraway is more pessimistic about the potential of the feminization of manufacturing and of labour more generally to generate more equality between men and women, at work and in society at large. Opportunities have arisen but these are concentrated in the labour-intensive, low-wage sectors of manufacturing.

Gender is so deeply embedded in the practices of production that market mechanisms are unlikely to remedy these inequalities. In other words, integration into 
waged work is necessary but insufficient to overturn the gendered hierarchies present in the relations and structures of production. (p. 167)

The theoretical contribution of these books is to lead us to integrate but reassess the postmodern paradigm and to better understand global gender processes. Bradley proposes an agenda for change that I would adhere to. It acknowledges the postmodern legacy, but does not reject the ideal of sisterhood, as a political, though not structural, common identity (p. 87): we should be optimistic about the potential of transversal politics based on the search for commonalities.

\section{References}

Bradley, H., Erickson, M., Stephenson, C. and Williams, S. (2000) Myths at Work. Malden, MA: Polity Press.

Butler, J. (1990) Gender Trouble, Feminism and the Subversion of Gender. London: Routledge.

Butler, J. (1993) Bodies That Matter: On the Discursive Limits of Sex. London: Routledge.

McRobbie, A. (1978) 'Working Class Girls and the Culture of Femininity', in Centre for Contemporary Cultural Studies, Women Take Issue, pp. 97-108. London: Hutchinson.

McRobbie, A. (1994) Postmodernism and Popular Culture. London: Routledge.

McRobbie, A. (2004a) 'Reflections on Young Women and Consumer Culture', paper presented at HM Treasury, London, as part of the AHRC Cultures of Consumption programme.

McRobbie, A. (2004b) 'Notes on "What not to Wear" and Post-Feminist Symbolic Violence', Sociological Review 52(2): 97-109.

Morgan, D. (2006) 'The Crisis in Masculinity', in K. Davis et al. (eds) Handbook of Gender and Women's Studies, pp. 109-23. London: Sage.

Skeggs, B. (1997) Formations of Class and Gender: Becoming Respectable. London: Sage.

Walkerdine, V. (1990) 'Video Replay: Families, Films and Fantasy', in M. Alvarado and J.O. Thomson (eds) The Media Reader, pp. 339-58. London: British Film Institute. 